\title{
OPTICAL AND ELECTRICAL MEASUREMENTS OF LOW-TEMPERATURE InAlAs
}

\author{
K.P. Korona, A. Wysmolek, R. Bożek, M. Kamińska, J.M. Baranowski \\ Institute of Experimental Physics, Warsaw University \\ Hoża 69, 00-681 Warszawa, Poland \\ AND E.R. WEBER \\ University of California, Berkeley, CA 94720, USA
}

\begin{abstract}
Photoluminescence, photocurrent, thermally stimulated current and photoinduced current transient spectroscopy measurements done on molecular beam epitaxy $\operatorname{In}_{0.52} \mathrm{Al}_{0.48}$ As layer, lattice matched to InP are reported. The investigated layers were grown on semi-insulating InP wafers, at temperature range from 215 to $450^{\circ} \mathrm{C}$. It was found that the Fermi level was pinned to a dominant midgap center (most likely similar to EL2 center). Moreover, there were at least 7 other defects but with much smaller concentrations. Their activation energies were equal to $0.076,0.11,0.185,0.295$, 0.32 and $0.40 \mathrm{eV}$. The layers exhibited a very low luminescence and a small photocurrent.
\end{abstract}

PACS numbers: 71.55.Eq, 73.60.Br, 78.55. Cr

Molecular beam epitaxy (MBE) $\operatorname{In}_{0.52} \mathrm{Al}_{0.48} \mathrm{As}$ layers grown on InP substrate are an important material for fabrication of transistors, photoreceivers and opto-electronic integrated circuits. The discovery that GaAs can be grown by MBE in low substrate temperature $\left(200^{\circ} \mathrm{C}\right.$ and below) producing a high-resistive layer (so-called low-temperature (LT) GaAs) created an idea to produce low-temperature layers of the other III-V compounds (InP [1], InAlAs [2]). The objective of this work was to examine basic electrical and optical properties like resistivity, photoconductivity, photoluminescence and defect levels of LT InAlAs layers. Analogically to LT GaAs [3] the high off-stoichiometry was expected, resulting in high concentration of defects.

MBE In I. $_{22} \mathrm{Al}_{0.48} \mathrm{As}$ layers lattice matched to InP were grown on semi-insulating InP substrate. The temperatures of growth and annealing for the samples studied are given in Table.

Resistivity versus temperature measurements were carried out in the temperature range $12-300 \mathrm{~K}$. It was observed that the resistivity of the InAlAs layers was higher than the resistivity of the substrate sample no. G55. In the region above $250 \mathrm{~K}$ the resistivities of the InAlAs samples and of the InP no. 1163 sample were similar. In lower temperatures the resistivity of no. 1163 sample was significantly 
TABLE

\begin{tabular}{c|c|c}
\hline \hline Sample number & Growth temperature & Annealing temperature \\
\hline 982 & $450^{\circ} \mathrm{C}$ & unannealed \\
985 & $230^{\circ} \mathrm{C}$ & $500^{\circ} \mathrm{C}$ \\
1153 & $200^{\circ} \mathrm{C}$ & $500^{\circ} \mathrm{C}$ \\
1154 & $215^{\circ} \mathrm{C}$ & $500^{\circ} \mathrm{C}$ \\
1155 & $230^{\circ} \mathrm{C}$ & $500^{\circ} \mathrm{C}$ \\
1158 & $245^{\circ} \mathrm{C}$ & $500^{\circ} \mathrm{C}$ \\
1159 & $260^{\circ} \mathrm{C}$ & $500^{\circ} \mathrm{C}$ \\
1160 & $275^{\circ} \mathrm{C}$ & $500^{\circ} \mathrm{C}$ \\
1162 & $450^{\circ} \mathrm{C}$ & $500^{\circ} \mathrm{C}$ \\
1163 & $450^{\circ} \mathrm{C}^{*}$ & $500^{\circ} \mathrm{C}$ \\
G55 & $230^{\circ} \mathrm{C}$ & $500^{\circ} \mathrm{C}^{* *}$ \\
G5 & \\
*InP substrate annealed in MBE chamber with the continual pres- \\
ence of As. The no. 1163 and no. G55 were comparative samples. \\
**The no. G55 sample was previously the no. 1155 sample but an \\
In T. $_{0.52} \mathrm{Al} l_{0.48}$ As layer was removed.
\end{tabular}

higher than resistivity of other samples. It suggests that the procedure of fabrication of InAlAs layers made some changes in InP substrate (i.e. in no. G55 sample). The conductivity activation energy was equal to $0.46 \pm 0.05 \mathrm{eV}$. Contrary to LT GaAs, no hopping conductivity was observed in measured LT InAlAs layers, which was probably due to relatively high growth temperatures.

Photocurrent spectra were changing significantly from measurement to measurement. It was probably due to some metastabilities caused by defects present in samples. For example, quenching of photocurrent in the range of photon energy $0.85-1.4 \mathrm{eV}$ and excitation of persistent photocurrent in temperatures below 100 $\mathrm{K}$ were observed. In spite of these problems, some regularities could be observed. In most of the InAlAs layers a weak band starting at $h \nu=0.85 \mathrm{eV}(\lambda=1.4 \mu \mathrm{m})$ was observed. This band did not exist in InP-substrate samples. In all samples strong photocurrent band 1.15-1.45 eV was observed.

Thermally stimulated current measurements showed presence of few types of defects in the investigated samples but the signal was very low. A characteristic electric current value in the peak was in the order of $0.1 \mathrm{pA}$. Taking into account expected high defect concentration, such small TSC signal can be explained only by very high recombination rate. In point of fact, very high rate of photocurrent transient was observed (except some samples at temperature below $100 \mathrm{~K}$ where persistent photocurrent existed).

Results of photoinduced current transient spectroscopy (PICTS) are shown in Fig. 1, where spectra of InAIAs layer and of InP substrate are compared. Seven 
deep centers with activation energies $E_{\mathrm{a}}: 0.076 \pm 0.005 \mathrm{eV}, 0.11 \pm 0.07 \mathrm{eV}, 0.11 \pm$ $0.01 \mathrm{eV}, 0.185 \pm 0.01 \mathrm{eV}, 0.295 \pm 0.02 \mathrm{eV}, 0.32 \pm 0.05 \mathrm{eV}$ and $0.40 \pm 0.04 \mathrm{eV}$ were found. The four centers with $E_{\mathrm{a}}$ between 0.185 and $0.40 \mathrm{eV}$ existed in all samples. The three centers with $E_{\mathrm{a}}=0.076$ and $0.11 \mathrm{eV}$ were absent in no. G55 sample where InAlAs layer had been removed from. In samples grown at temperatures

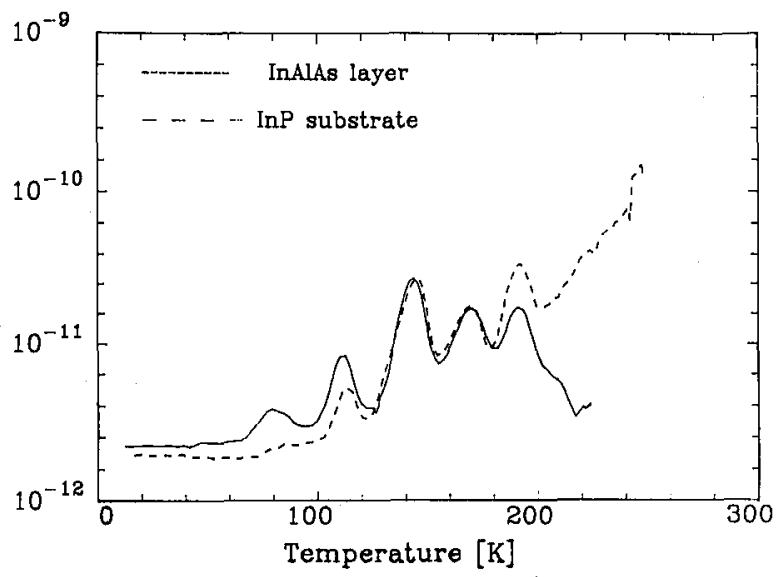

Fig. 1. PICTS spectra of LT InAlAs layer grown at temperature $245^{\circ} \mathrm{C}$ (no. 1155) and of the InP substrate sample (no. G55).

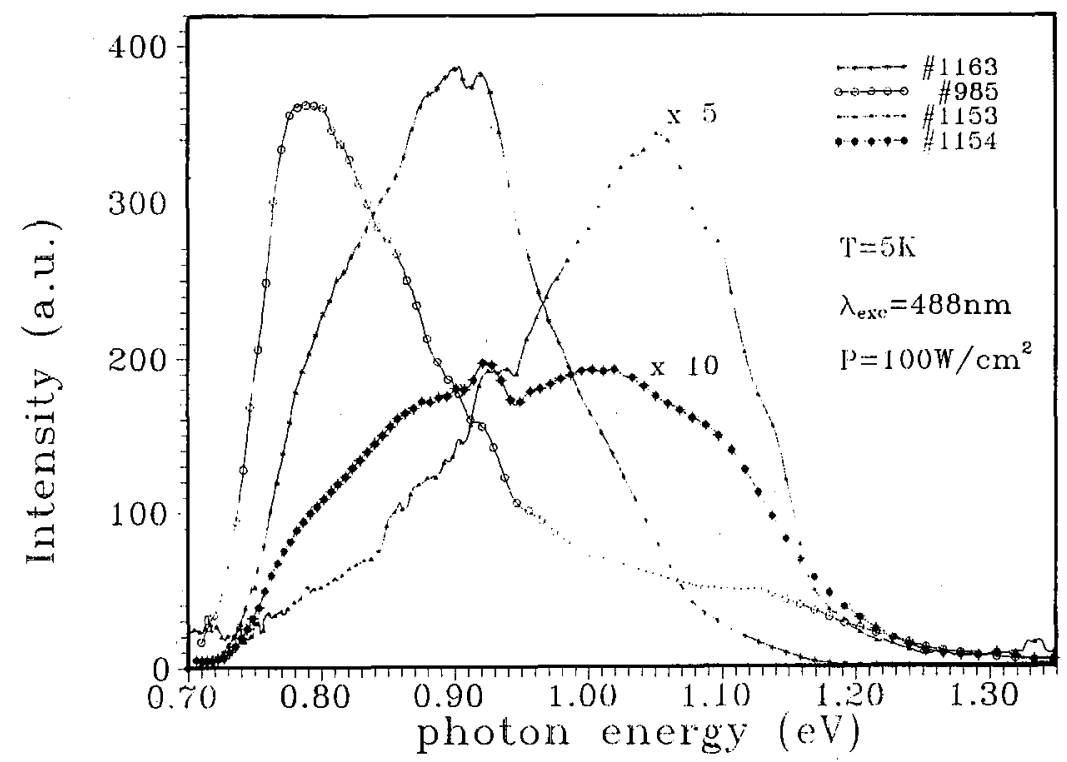

Fig. 2. Photoluminescence spectra of InAlAs layers. 
above $275^{\circ} \mathrm{C}$ persistent photocurrent band existed at temperatures $40-100 \mathrm{~K}$, which disabled us from observing these peaks.

Photoluminescence (PL) measurements were performed at the temperature $5 \mathrm{~K}$ under excitation with $488 \mathrm{~nm}$ line of $\mathrm{Ar}$ ion laser with power density about $50 \mathrm{~W} / \mathrm{cm}^{2}$. All the layers showed weak PL signal (Fig. 2). Moreover, the amplitude of the signal strongly changed depending on the position of the beam on the sample. PL spectra consisted of a few broad bands starting at $1.24 \mathrm{eV}(1.0 \mu \mathrm{m}), 1.13 \mathrm{eV}$ $(1.1 \mu \mathrm{m}), 1.0 \mathrm{eV}(1.2 \mu \mathrm{m})$ and $0.85 \mathrm{eV}(1.4 \mu \mathrm{m})$. There was no clear correlation between the shape of the spectra and the growth conditions of the layer. In some spectra (no. 985, no. 1153) it was possible to observe a luminescence identical to that related to $\mathrm{Fe}$ in $\mathrm{InP}$.

In summary, some deep levels were found in LT InAlAs layers, but their concentration was much smaller than expected. As an explanation of low TSC and photoluminescence signal high carrier recombination rate was proposed. The deep pinning of Fermi level and quick carrier recombination suggested existence of a dominant deep level. The origin of this level is unknown but the metastability of photocurrent is indicative of the defect similar to EL2 defect in GaAs.

The work was financially supported by the Committee for Scientific Research grant number 204249101.

\section{References}

[1] P. Werner, Z. Liliental-Weber, P. Dreszer, K.M. Yu, E. Weber, Z. Reck, R. Metzger, in: Proc. 7th Conf. Semi-Insulating III-V Mater.

[2] J.Ch. Garcia, J.P. Hirtz, in Ref. [1].

[3] M. Kaminiska, E.R. Weber, Proc. 16th Int. Conf. Defects Semicond., Trans. Tech. Publ., Switzerland 1992, p. 1033. 